\title{
Effects of Thuja Occidentalis as an alternative remedy in the treatment of Papillomatosis in Cattle
}

\author{
A Shakoor, S A Muhammad*, M Kashif, Z U Rehman, A Hussain and M R Hameed \\ College of Veterinary and Animal Sciences, \\ Jhang. Sub-campus, Univerisity of Veterinary and Animal Sciences, Lahore - Pakistan \\ *Correspondence author email: jimmyshahjee@yahoo.com \\ Received: 11-08-2011, Accepted: 09-09-2011, Published Online: 02-12-2011 \\ doi: $10.5455 /$ vetworld.2012.118-120
}

\begin{abstract}
Papillomatosis is a condition in farm animals and is treated by surgical excision or application of certain caustic agents. Contrary to it, two cattle with teat warts were treated by an alternative method by using the thuja occidentalis (thuja-30, a homeopathic medicine) @ 10 drops Per os twice a day for a span of 3 weeks and lead to complete recovery.
\end{abstract}

Key words : Cattle, thuja-30, Homeopathic Medicine.

To cite this article : Shakoor A, Muhammad SA, Kashif M, Rehman ZU, Hussain A and Hameed MR (2012): Effects of Thuja Occidentalis as an alternative remedy in the treatment of Papillomatosis in Cattle, Vet. World 5 (2): 118-120, doi: 10.5455/vetworld.2012.118-120

\section{Introduction}

Papillomatosis is a solid outgrowth of epidermis and appears in various sizes, shapes and most common in cattle and horses affecting any part of the body (Radostits et al., 2007) assuming the appearance of cauliflower. It is caused by host specific pappiloma virus which are six in number named as bovine papilloma virus (BPV)-1, BPV-2, BPV-5 causing fibro papillomas and BPV-3, BPV-4 and BPV-6 which cause true epitheliomas. BPV-1 causes warts on teat and BPV-2 brings about cauliflower cutaneous growth. Exposure to sunlight (ultraviolet rays) may also be an etiologic factor. Warts can be treated by surgery and cryosurgery (Valentine, 2004). Besides it, autogenous vaccine is also claimed to be of variable efficacy. The objective of this case study was to try some other cost effective alternative method of treatment belonging to some other system of treatment and was either to ratify or to refute the lofty claims made by the corresponding system like homoeopathy.

\section{History and Clinical Examination}

Two crossbred cattle were brought to the Veterinary Teaching Hospital, Department of
Clinical Studies, College of Veterinary and Animal Sciences, Jhang. One was recently aborted, nonlactating cow and other was non-pregnant adult heifer. Both had warts of variable sizes (marble to tennis ball size) on teats causing the unsightly appearance. Obviously, these looked like cauliflower appearance. Upper $1 / 3^{\text {rd }}$ part was hard and black in color but lower $2 / 3^{\text {rd }}$ part was semi soft and reddish in color indicating highly vascularized. These covered the whole outer surface of all teats. Some warts were covered by hard encrtustation of dung having red raw surface underneath. History indicated their progressive emergence for the last 4 month. During the last 15 days, heavy doses of strepto- penicillin (Polybiotic $5 \mathrm{gm}$ ) in combination with Non-steroidal Antiinflammatory drugs (Diclofenic Sodium) and lastly steroidal preparation (Solon $-\mathrm{M}$ ) were got used by local veterinary compounder but all in vain.

\section{Treatment}

In this predicament, it was thought to be used an alternative method of using a plant derivative homoeopathic preparation available in market with a brand name of Thuja-30 for 
humans. It was prescribed to be used by adding 10 drops on a lump of Jaggery (Gur) per.os twice a day for 15 days and asked the owner to get their animal inspected after 2 weeks. Their was about $75 \%$ reduction in size of all warts which became shriveled and hard up to the base but tightly stuck to their bottom. Some small sized hard warts sloughed off leaving their scar. Keeping in veiw the miraculous effect of the said medicine, its use was advised to continue for another week long period. After 22 days close inspection indicated the complete peeling off all warts leaving their scars of variable size and all teats of both cows were normal and devoid of any defect or complication affecting the size and length.

\section{Discussion}

Surgical intervention was not adopted with this apprehension that it will cause big wounds leading to delayed recovery because of contamination during sternal recuumbency besides myiasis owing to fly season. Thuja occidentalis (Mor Punkh vernecular name in Urdu) is a quite common small doom shaped plant found in orchards or Gardens. Thuja-30 potency drug is prepared from the mother tincture of its leaves (Madrewar, 1999) This drug is quite popular in human being for removing warts in general and black cauliflower like in particular (Hussain, 1988 ) It acts on skin, blood, gastrointestinal tract, kidney and brain but mainly the action is on skin and genitourinary organs ( Maclead, 1992). This is of real importance in the treatment of skin conditions accompanied by the development of warty growths which bleed easily (Madrewar, 1999). Papillomatous warts are especially amenable to this drug. It is indicated in polyp, epithelioma (Maclead, 1992, Verma, 1998). This wonderful effect may be ascribed to its various chemical constituents i.e Dextro-pinene, Dextrothujone, thujine, laevo-fenchone and pinpierin (Felter, 1904).

The homeopathic treatment takes some time to exert its effect but the results can be observed. When sessile ulcerated wart present single or in clustors and bleed easily. Caustieum-30 is recommended. In case of small numerous flat warts on the teats of heifers and cows- calcarea carbonica-30 is the effective remedy. In case of large flat warts developing mainly on the head and limbs, Dulcamara-200 is recommended. When warts are large and sharp-edged which may tend to bleed easily Aciduin nitricum-200 is considered suitable. If warts emerge in the genital areas, Sabina-30 is considered an excellent remedy. In case of small ulcers around the bottom of warts, Arsenic-30 is recommended.

In the present case, Cauliflower like appearance on teat skin lead to the selection of Thuja-30 (Madrewar, 1999). It proved its worth in 3 weeks. It is in line with the findings of Madrewar (1999) who describes 90\%, 95\% even $100 \%$ cure in various diseases (skin diseases like pityriasis, hyperkera-tosis, parakeratosis, pachydermia, urticaria and warts) which had been declared incurable by the other system of treatment. It was concluded that Thuja-occidentalis, a homeopathic drug may be considered as alternative of surgical intervention in case of warts having resemblance of cauliflower in cattle. It saves the owner to discharge the cumbersome job of daily antiseptic dressing, cost of antibiotics administration, meticulous cleanliness if be got it treated by surgical method.

\section{References}

1. Felter, H.W., (1904). A treatise on Thuja occidentalis- the therapeutic use of thoja. Lloyd Brothers, ohio. USA. Available from:www.Herbal therapeutics.net/thoja.doc.pdf. Accessed 2011 August.9.

2. Hussain, A., (1988). Homeopathic Pocket Materia Mediea. Kent Homeopathic Stores and Hospital. Homeopathic building Block No. 7, Sarghoda. Pakistan.

3. Maclead, (1992). The treatment of Cattle by Homeopathy. B. Jain Publisher's (P) Ltd. New Dehli. India. p. 139.

4. Madrewar, (1999). Therapeutics of Veterinary Homeopathy and Repertory. $2^{\text {nd }}$ Ed., B. Jain Publishers (P). New Dehli. India. p.290.

5. Radostits, O.M., C.C. Gay, K.W. Hincheliff \& P.D. Constable, (2007). Veterinary Medicine. A textbook of the diseases of cattle, horses, sheep, pigs and goats. Saunders Elsevier, New york, USA. p. 1421-23. 
Effects of Thuja Occidentalis as an alternative remedy in the treatment of Papillomatosis in Cattle

6. Shingle, J.N., (1994). Quick bedside Prescriber Awan Homeopathic Clinic, Mehrsuba Park, Yahya colony, Ghora Shah Road, Lahore.

7. Smith, D., (1999). Before and After Surgical operations. B. Jam publishers (P) Ltd. New Delhi. India. p.105-106.
8. Valentine, B.A., (2004). Neoplasia chap \#3. In: Fubini S.L and N.G. Duchame, editors. Saunders, St. Louis, Missouri.

9. Verma, S.P., (1998). Practical Handbook of Surgery with Homoepathic therapeutics. B. Jain publisher's Pvt. Ltd. New Dehli. India.p. 105. 